\title{
A stress test for the strong homogeneity thesis
}

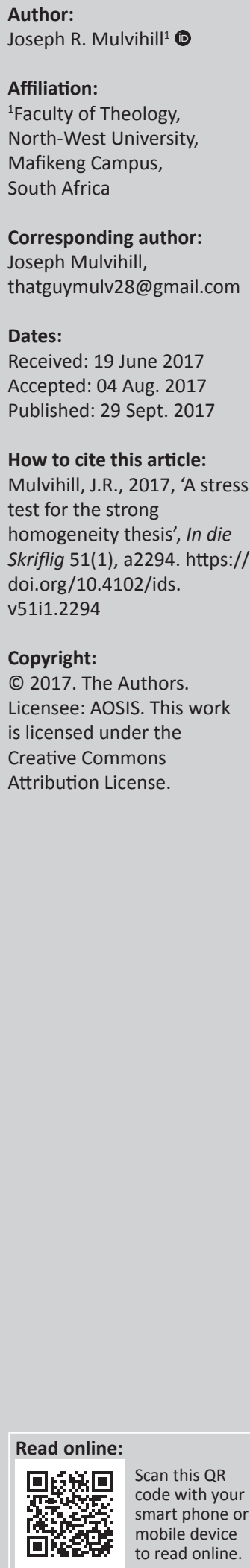

Over the last 30 years, there has been an attempted return to a particular way of framing and interpreting the primary Jesus narratives. This approach contextualises Jesus against the backdrop of the wider religious world. Proponents claim that the primary Jesus data was culled from a wide pagan template or common stock of ubiquitous religio-mythic concepts. I refer to this position as 'the strong homogeneity thesis'. Though this way of assigning literary causation and activity to the Gospel tradents has been largely rejected by scholarly community, it has been offered recently by some academics. In what follows, I offer a new way of evaluating this thesis that tends to avoid the shortcomings associated with past and present efforts to establish this way of explicating the Jesus tradition.

\section{Introduction}

A subcategory of the claim that the Gospels belong in the genre of mythology is a position that attempts to answer the question of literary causation. That is to ask what data and events best explicate the origination of the Gospel narratives. It has been said that the salient characteristics of the profile of Jesus of Nazareth find their origination in various antecedent figures featured in the Greco-Roman host culture of the era, even including features found in other precursor ancient near eastern cultures. I am going to refer to this idea as the strong homogeneity thesis in reference to the Gospels. ${ }^{1}$

Over the past 30 years there has been a subtle return to the strong homogeneity thesis that was formerly assumed to be a formidable objection to traditional Christianity (Carrier 2002; 2009; 2014; Casadio 2003:263; Harpur 2004:51; Harris \& Platzner 1995:255, 414-415; Jackson 1985:67; MacDonald 2000; 2015; Mack 1995:75-77; Miller 2010; 2015; Nabarz \& Matthews 1995; Price 2000:75-96; 2009; Price \& Lowder 2005; Rank, Raglan \& Dundes 1990:179-190; Robertson 1985:292294; Ruttimann 1986).

In the late nineteenth century, this thesis was a challenge to Christianity's uniqueness and credibility by way of a then new analysis and subsequent genre classification (Dupuis 1795; Priestly 1804; Strauss 1860:56). The Gospels were alleged to be second-century constructed Jewish amalgams of antecedent ancient near eastern and Greco-Roman pagan background religious beliefs related to myths or Mystery religions (Bousset 1913:19-20; Bultmann 1953:15-16; 1962:7, 32-35; Carus 1902:416-425; Pfleiderer 1910:24-25). The four New Testament Gospels were, according to proponents of this theory, not to be considered reports of authentic historical events recalled but rather imaginative cultural composites, finding their genesis in the contours of long known pagan paradigms and narratives. Subsequent scholarship significantly challenged this analytic paradigm and New Testament scholars (Aune 1981; Boyd \& Eddy 2007; Evans 2006; Habermas 1996; Johnson 1996; Meier 1991; Metzger 1968; Pannenberg 1968; Porter \& Bedard 2006; Rahner 1955; Sanders 1985; Vermes 1973; 1983; Wright 1992; 1996; 2003) have largely found this thesis wanting and moved on.

The claim that the Gospel narratives are mythical has had a long pedigree; it seems as though Jesus' original followers had to meet similar challenges (1 Tm 1:4; 4:7; 2 Tm 4:4; Tt 1:14; 2 Pt 1:16; see Bruce 1976:643-647; Dinckler 1962:487; Hughes 1984:747-749; Keener 1993:608, 631, 637, 727; Oswalt 2009:loc. 439, 3131). Relegating the Gospels to a mythic category is still common considered by some to be an esteemed choice to designate an alternative genre assignment to this particular first-century content. The designation of myth as a genre for the Gospels - from the least-informed Internet sceptic to credentialed scholars of the ancient world such as Richard Carrier (2005:145-151; 2009:14; 2014:56-60) or Robert Price (2000:250, 259-260; Price \& Lowder

1.This article was directly adapted from my doctoral dissertation submitted to North-West University entitled 'The dependence between the Gospels and pagan literature with regard to death and return; towards a method for evaluation'. 
2005:145-151) to the anonymous sceptical blogger - is so ubiquitous that it is difficult to evaluate myth as an appellation.

\section{Assimilation and ethnocentricity}

The idea that the Gospel portraits of Jesus were the result of religious, mythic or cultic homogeneity is an old one. To be sure, there is conceptual borrowing to some degree amongst all faith traditions. Religious assimilation was widespread in ancient cultures, where annexation and conquest were common. The Persians, for example conquered many diverse cultures in the ancient near eastern world and borrowed ideas from the conceptual capital of the conquered (Anon. 2008:xxxv; Waters 2014:73, 78). However, ethnocentrism was also a ubiquitous cultural phenomenon, and the militarily dominant group would strive to retain the sociological momentum of their conquests by way of asserted conceptual superiority of their own ideas over against any that might otherwise have been adopted from their defeated adversaries (Adams \& Barden 1952:1-54; D'Souza 1995:30-36; 2002; Yahaya 2008:9-12). When the Romans came to dominate the ancient world, one can most easily see this adoption and retention interplay in their incorporation and transformation of the Greek pantheon into a more Roman polytheistic hierarchy (Beard 2012a:166-170; Cameron \& Athon 2004; Grant 1986:4-12; Johnson 2009:36-37; Stark 2016:31-32).

Assimilation and integration, as well as ethnocentricity, were common features in cultures given to the conquest ethic (Rajak 2008:61; Stark 2016:29). Ancient Jews were far more ethnocentric and religiously exclusive than their ancient neighbours, even while being largely subjugated, enabling them to maintain a strong minority presence and to generally resist assimilation within those host cultures (Hurtado 1988:20-22; 2005:26-30, 111-134; 2016; Rajak 2008:61-62; Sanders 1992:8). Indeed, ancient Jews were known for their religiocultural exclusivity. This certainly does not mean that they never attempted religious assimilation; the covenantviolating attempted integration of pagan polytheism by Jews in the ancient world is well documented (Johnson 2009:112; Sanders 1992:38-50, 303; Williams 1998:81-82).

At the time of Jesus and his followers, Jews were dominated by the world power of Rome, and first-century Jews who adopted some features of their particular pagan subjugation matrix were likely present. Additionally, there was assimilation and integration activity as Rome adopted and transformed ideas from the cultures it conquered (Beard 2012b:174-175; Stark 2016:32). The crucial question is how heavy an emphasis should be placed on this one side (adoption and assimilation) of the social influence spectrum. The 'other side' - that of insistent, implemented cultural exclusivity - must be factored in to the equation if the investigator is to avoid overestimating the role of integration and assimilation. Thus, some rigorous criteria are vital when assessing the strong homogeneity literary approach to Gospel narrative causation and explication of the Gospels subsequent sociocultural power to enable one to come to an informed and balanced conclusion.
Currently, the three credentialed champions of this thesis are Richard Carrier, Dennis R. MacDonald and Robert M. Price. Carrier holds a doctorate in ancient history from Columbia University, MacDonald a doctorate in New Testament studies from Harvard University - he is currently a professor of Religion and New Testament at Claremont Graduate University - and Price who holds two doctorates from Drew University, one of which he took in Systematic Theology in 1981 and the other in New Testament studies in 1993. All three scholars hold nuanced versions of a strong homogeneity thesis and defend their contentions publicly (Carrier 2005:145-151; 2009:14; 2014:56-60; Macdonald 2000:11, 22-23; 2015:1-4, 10; Price 2000:75-96, 250-260). There are other contemporary credentialed scholars who hold to similar forms of this thesis in their published work (Africa 1974; Allegro 1970; Campbell 1972; Fogelin 2003; Frazer \& Frazer 1998; Harris \& Platzner 1995; Jones 1969; Krauss 2011; Mack 1988; 1995; 2001; Miller 2010; 2015; Nabarz 2005; Ruttimann 1986; Wolmarans 2008). These individuals are flanked by dozens of active, interested yet untrained non-professional scholars who sometimes land a rare publication opportunity (Murdock 1999) or resort to self-publication (Freke \& Gandy 1999). This last category of Jesus-mythers are individuals who, out of necessity, predominantly use the Internet to expound upon the subject of Jesus' alleged connection with parallel pagan ideas with no controls for their affirmations.

\section{The pressing need for a standard method}

Generally absent from critical works offered by proponents of the strong homogeneity thesis is a rigorous and robust academic method that readers can track to a relatively clear conclusion. This is true of both past and present scholars who were and are convinced of this particular way of explicating the authorship and cultural power of the Gospels. If a method is clearly specified, it will often preclude critical data that would significantly modify the strong homogeneity conclusion or undermine the particulars of the claim in question. Authors committed to this thesis rarely explain how they constructed their method or why they chose the methodology they employed. Finally, there is troubling absence of bias qualification in these works; this is pointed out time and again by scholars critical of the strong homogeneity thesis (Alsup 1975:215-216; Boyd \& Eddy 2007:21-24; Riches \& Millar 1985:46; Sandmel 1962:1-2). My treatment attempts to confront these shortcomings by offering a method of literary evaluation that addresses these issues.

Are the past and present approaches attempting to establish the strong homogeneity idea adequate, or is there a better way? How can one responsibly compare and analyse the Gospels in relation to similar pagan data to better evaluate the credibility of the strong homogeneity thesis?

A handful of logical fallacies are prevalent amongst those who espouse strong homogeneity arguments, such as the following: 
- The post hoc ergo propter hoc fallacy: the assumption that simply because some thing, event, or idea precedes another, that particular antecedent must therefore be causal for the thing, event, or idea to which it is being compared. The error in thinking is that A precedes B and therefore must have caused B. Put another way: correlation is not necessarily causation.

- Another one is the genetic fallacy: the assumption that if one can explain the origin of an idea, that explanation refutes that idea. Expressed another way: it is the pitfall of confusing credibility with plausibility and thereby bypassing the independent reasons for believing the claim in question. ${ }^{2}$

- There is also the fallacy of hasty generalisation: this is the mistake of irresponsibly connecting data without accounting for vital counter-data.

- The preceding type of parallel argument can also beg the question. In the case of the Gospels, this would look like beginning with a crucial presupposition dismissing their historical veracity without the requisite argumentation and then arguing to establish pagan parallel accounts, and unsurprisingly, on that basis to dismiss their historical credibility. In other words, 'begging the question' is assuming what one sets out to prove, or simply restating the conclusion as a premise in a syllogism.

- Avoidance of the fallacy of false analogy is unequivocally central, as analogy is minimally needed to establish genetic or causal relationships.

- The most obvious fallacy that threatens to undermine the entire matching process, in any situation, is that of failing to heed the law of the undistributed middle. Simply put, just because two entities have one or even multiple characteristic(s) in common does not thereby mean that they have everything in common and thus are to be considered identical - in our case, a genre or literary identity relationship. I have ears, an elephant has ears, and yet I am not an elephant. If I fail to 'distribute', consider or enumerate all of the other critical differences between the two entities under analysis, I will surely make an invalid connection and consequently be placed with the pachyderms in the zoo. The baseline procedure of those who support the strong homogeneity idea has always been to find parallel items, events, or ideas and then to extrapolate generic and genetic relationships between the formerly disparate datum. A failure in analytic diligence and care concerning this crucial issue inevitably causes analytical failure with any parallel proposal.

One wants to avoid these common mistakes in any attempt to establish a link between distinct data. These issues raise a crucial question: Just what does constitute a sufficient amount of evidence to make a parallel claim plausible? Isn't this practice hopelessly subjective?

2.This usually involves attempting to discredit an idea by explaining the psychological motivations for its inception and retention without dealing with the reasons for the motivations for its inception and retention without dealing with the reasons for the idea itself. To be sure, the source or origin of an idea is important, but this is a cheap and illegitimate way to win an argument - one that is often employed by politicians in public venues.
Though one can never get beyond the reach of individuated subjectivity, one can strive to strengthen the verisimilitude of conclusions. In an effort to overcome the fallacies mentioned above and address the particular analytic vulnerabilities highlighted by critics of the strong homogeneity thesis, proposing a new combination of evaluative methodologies for consideration could be beneficial for adding plausibility to future comparative efforts. The hope is that this constellation of borrowed controls could be profitably employed to compare Jesus to any parallel character at any time chronologically.

One also wants to attempt to qualify one's biases and presuppositions to aim asymptotically toward objectivity and delimit subjectivity. Further, to take cues from professionals in an analytic field distant from your own is academically prudent. That these contributors listed below fail to share my particular biases and presuppositions, is also a clear benefit in qualifying bias.

In what follows, there will be an exposition of scholars and particular controls that will be utilised in this endeavour. The method itself will then be briefly expressed with some explanatory commentary. The full doctoral thesis attempts to implement this combinatorial process with two chosen exemplars in comparison to Jesus of Nazareth. Unfortunately, space restrictions disallow that application here.

\section{Contributors to the rubric Walter Burkert}

Dr Walter Burkert, long known to be an expert in the field of ancient near eastern religion and culture, is an emeritus professor of Classics at the University of Zurich. He has been one of many professional scholars attempting to connect ancient stories with an antecedent tale that might serve as an explication of its origin. Burkert is extremely careful to avoid drawing a misleading or spurious parallel in the scholars' pursuit of discovery and dissemination. Burkert (1992:88) describes the necessity of bypassing superficial similarities and instead focusing on 'complex structures' that link the data. He (Burkert 1992:88) provides a few examples of complex structures to discover when attempting to link the data:

Instead of individual motifs, therefore, we must focus on more complex structures, where sheer coincidence is less likely: a system of deities and a basic cosmological idea, the narrative structure of a whole scene, decrees of the gods about mankind, or a very special configuration of attack and defense. (p. 88)

Burkert emphasises that one must avoid ubiquitous language and grand thematic similarities when attempting to draw connection between, say The Odyssey and the Gilgamesh Epic. These few individuated motif similarities are all too common to carry a responsible parallel or linking hypothesis. Conversely, Burkert tells us that if words tend to be seen nowhere else in the mythic or religious matrix of the character in question, special attention should be given to these linguistic anomalies so long as they are not connected to 
some common stock of shared cross-cultural mythical, existential, or religious themes. These words should be further mined for specific conceptual or underlying use in the employment of this language between the proposed parallels in question. ${ }^{3}$ Burkert makes clear that even a number of links that are complex and numerous might not carry the whole burden of proof for borrowing from one to the other. I echo this qualifier.

\section{Martin Litchfield West}

Although one must take great care with the two sides of the data, Martin Litchfield West, an internationally recognised Oxford scholar in Classical Antiquity and Philology, points out that one must look for 'striking similarities' in an ancient data genetic coupling project. Further, the striking connections must be assessed against the presence of strong dissimilarities (West 1997:viii).

West (1997:viii) rightly points out that there does not need to be 100 per cent correspondence or some sort of airtight identity relationship in order to make a parallel case. Surprisingly, he carries this further by suggesting that the similarities can sometimes be outnumbered by the differences but that a formidable homogeneity relationship can nonetheless be carefully determined (West 1997:viii-ix). However, the similarities must be strong - have a particularly high degree of correspondence - and there must be a multiplicity of these robust common features. To demonstrate his point and prevent the word striking from becoming hopelessly subjectivised, West (1997:viii-ix) provides an example of Semitic idiom expressed in the Greek myth text, completely unexplainable apart from borrowing.

\section{Jaan Puhvel}

The Johns Hopkins University scholar Jaan Puhvel follows these professional scholars in his comparative process concerning myth. Puhvel (1987:29) echoes West, and like him believes that the parallels proposed must be numerous and share an extraordinary proximate locus of meaning. ${ }^{4}$ In other words, many connections must be deduced, and then each parallel must be dissected and placed in context in order to evaluate whether the words used carry a similar linguistic function (Puhvel 1987:29-30).

\section{Charles Penglase}

The ancient near eastern myth specialist Charles Penglase (1994) gives us some criteria to consider for the rubric, prefaced by yet another warning regarding this undertaking:

3.Burkert cites the single-mention 'Tethsys', as spouse or concubine of Oceanus in Homer, as a translation of 'Tiamat' as wife of Apsu in Enuma Elish. To this point the mentioning of Tethsys appears to be utterly unique in all of mythology and ancient mentioning of Tethsys appears to be utterly unique in all of mythology and ancient lore. Burkert (1992:92) then posits that because of this special case and its other narrative 'holdover' or parallel from borrowed narrative structure.

4.Puhvel recounts the parallel scenes of 'Typhon' in the sea (Nonnos) and 'Ullikummi' (a giant stone monster of Hittite myth), in which numerous physical details and spatial arrangements are designated in like terms, in similar narrative context, and in parallel sequence.
[']Difficult['] and [']hazardous['] are words which describe the study of Mesopotamian influence in Greek myths, and an appropriate method is essential. To establish influence, or at least the likelihood of influence, there are two main steps. First it is necessary to establish the historical possibility of influence, and then the parallels between the myths of the areas must fulfill a sufficiently rigorous set of relevant criteria. (p. 4)

For Penglase chronology is king. This control will also be prominently featured in our rubric. Notice too his emphasis on explication and application of a rigorous methodology. I find that all four of these careful scholars shackle themselves to criteria in order to avoid the copious potential mistakes attendant with the type of project outlined above - the point being that the evidence has to be quite strong for a proposal of this type. Penglase (1994) goes on to provide a few further suggestions:

It is all too easy to run eagerly after superficial parallels which cannot really be sustained under a closer scrutiny. Accordingly, the parallels must have similar ideas underlying them and, second, any suggestion of influence requires that the parallels be numerous, complex and detailed, with a similar conceptual usage and, ideally, that they should point to a specific myth or group of related myths in Mesopotamia. Finally, the parallels and their similar underlying ideas must involve central features in the material to be compared. Only then, it would seem, may any claim stronger than one of mere coincidence be worthy of serious consideration. (p. 4)

Penglase is extremely helpful here. He echoes both West and Burkert in his insistence that the parallel features be plentiful, and he concurs with Burkert that they must be complex and specific, as opposed to ubiquitous and general. All these scholars are conscious of danger equivocation in their projects. Penglase also points out that there should be a common concept or usage underlying the proposed linguistic, event, or ritual parallel. In addition, he wants to avoid possible peripheral connections and focus instead on axiomatic features of the narratives under analysis. In his book Penglase (1994:215) includes geographic considerations in the transmission of ideas within a predominantly oral culture - a particular methodological feature we will not be implementing in our analysis.

Consequently, the seven controls for analysis and evaluation of a genetic link are as follows:

- Determine an exemplar for evaluation

- Present primary sources with relevant context

- Chronology

- Number of contacts, specific, detailed, complex, or nonsuperficial features (number and the quality of said contact points)

- Strength of word or event similarity

- Centrality of the death and return event

- Competition amongst pagan accounts

This method consciously combines the controls of Burkert, West, Puhvel and Penglase for just over half of the cumulative criteria. These scholars have been seen as successful in their careful establishment of historical causation, linkage and 
development. The desire is to utilise them to analyse the particular claims of scholars in reference to the possible pagan pedigree of the Gospel narratives. The additional categories offered by this author are to determine an exemplar for evaluation, to present primary sources with relevant context and the centrality of the death and return event respectively.

\section{A method offered}

Perhaps the most formidable challenge in this project has been the establishment of criteria. A rubric is axiomatic to any analytical project. Without it one would have been faced with the philosophically arduous task of attempting to prove a negative - to verify that no ancient accounts substantially parallel the Gospel narrative. Since no one is in possession of every ancient writing and there is no plenary awareness of all ancient events, investigation of this issue has to be discreet. Perhaps by offering a method by which future scholars are aided in assessing and presenting these types of strong homogeneity claims, one could acquire an increased confidence.

The initial suggestion is to find actual ancient examples of pagan personages that are alleged to match Jesus' New Testament profile (category \#1 - i.e. Horus, Zalmoxis, Mithras, Hercules). It is irresponsible and unscholarly to present the ideas one is attempting to use as a causal explanation and framing them as subconscious noetic phenomena carried by the Zeitgeist of the day without providing substantive source context and a target archetype. For one, this ancient pagan Zeitgeist is extremely difficult to determine without multiple streams of corroborative data culled from trusted sources. Second, concrete examples give those investigating the claim a way to assess it. If someone is free to cull ideas from every ancient culture or any source to make a parallel case it is nearly impossible to fail to match any idea or person to a canvass so broad. One wants to avoid stacking the deck and one way to regulate tendentious coupling is by proffering concrete exemplars for evaluation for those individuals that you are trying to convince.

Next, the scholar would need to produce all the critical original source data from the ancient pagan character with regard to the question of similarity (\#2). They would be required to include more than a sentence or word or phrase, that is to say, the context was presented as far as it was deemed relevant to the comparative enterprise at hand. In addition to this, where it was possible, this method requires multiple ancient sources to evaluate the data in order to highlight similarity and present contrast. ${ }^{5}$ The inclusion of multiple sources of commentary with regard to the proposed matching figure in question helped inform one particular pillar of the method proposed that falls under the heading entitled, 'Competition'. The 'competition' (\#7) methodological category or criterion was culled indirectly from a number of scholars who evaluate ancient data for connections consistently in their chosen vocation (see above). This criterion simply evaluates whether the particular ancient sources expressing the ideas or activity of the pagan character generally supports one another or conversely, are at odds with one another. The question the 'competition' category attempts to assess is: 'Is there a coalescing of the narrative strands under analysis or clear contradiction between the accounts?'

The reason to include these particular analytic criteria of 'present primary sources' (\#2) and 'competition' (\#7) is because they lay bare the divergence that is crucial for qualifying an effort at assessing whether there is a data match. In the full dissertation, the determination of primary sourcing was by earliest pagan character citation chronologically, then number of ancient copies for evaluation and finally, the pedigree of chronicler. ${ }^{6}$

For example, if one is allowed to pick and choose from consistently divergent accounts of a hero or deity and then append them all to the salient ideas and activities of Jesus, then again, a match is being made in a tendentious and unfair manner. An excellent example of this is when parallels are presented between Jesus and the Egyptian god Horus. The ancient literature related to Horus is voluminous and highly divergent in many details (Griffith 1961:12; 1996:118; Meltzer 2003:164-168; Short 1985:vii, 39; Watterson 1985:82-83; Wilkinson 2003:202). For someone to run a word search over era after era of ancient Egyptian data to mine any link between the god Horus and Jesus, to not find ideas and actions that match Horus and Jesus now becomes unlikely. So, the 'competition' criterion is to keep everyone honest, and where applicable, this control is to help determine whether or not there are either numerous, strongly conflicting accounts in both descriptive activity and concepts for the pagan character offered as a match with Jesus. This gives a qualifier to help the individual weighing the parallel case under question to not miss crucial details that certainly should affect the plausibility of the link offered. These first two steps (\#1: Determine an exemplar, and \#2: Present primary sources) are important for at least three reasons:

Firstly, including literary examples removes the idea from the abstract realm of discourse and allows the proposed thesis to be analysed. Most proponents of the strong homogeneity thesis frequently attempt to offer a point of reference, but then fail to include source context.

Secondly, offering the best possible sources for the exemplars with context, aids the reader in understanding the ideas and events that are being proposed in the case at hand, to link the pagan character under consideration to Jesus of Nazareth.

6. Is the source author known to be reliable in reporting other events, or maybe a questionable unknown individual, or somewhere in between on the spectrum of questionable unk? trustworthiness? For example, ancient Roman historian Cornelius Tacitus seems to have a high pedigree for accuracy in reporting (Mellor 1999:76-90). Appolodorus of Alexandria might be representative of the opposite pole of 'pedigree' category, a he offers less data for consideration, achieves less correspondence, is less mentioned and used by contemporaries as well as subsequent writers. The Greek historian, Herodotus, falls somewhere in between these two. 
And finally, many scholars who have encountered this resurgent homogeneity question over the last century have strenuously objected to the links offered by proponents. Many scholars who disagree point out that familiarity with original source documentation renders this strong homogeneity thesis untenable (Gasque 2004; Metzger 1968:4; Nash 2003:126-127; Porter \& Bedard 2006:89-90; Smith 1987:2535-2540). Presentation of pagan personages, along with oldest possible sources with responsible translation, is crucial to the evaluative process. The later the narrative, the stronger the likelihood of embellishment and accretion.

Chronological considerations (\#3) seem to be a logical initial point of assessing connection, as one cannot draw from another without an antecedent and a subsequent that has ostensibly adopted the features in question. The reason none of the aforementioned scholars, except Penglase, mentioned chronological considerations in their description of controls, is simply because in all of their (Puhvel, Burkert, West) investigations and analyses there was little question as to which story came first in the history of the traditions that they were comparing.

Then one has to look for 'numerous' or quantifiable similarities (\#4) within the accounts in question along with key dissimilarities as well. It is crucial to understand that differences alone do not suffice to deny a possible authorial link between accounts. The differences must be weighed and set over against the presence of 'complex, striking and numerous' similarities between the stories under analysis.

One has also to look for complex or intricate compound points rather than general ubiquitous features with which to compare. Just what are 'complex' points of similarity? Examples such as background system of deities, narrative structure, spatial arrangement in the narratives, presuppositional frameworks, general event similarity, character or personage descriptive matches, and many more are to be considered. A multiplicity of non-superficial interrelationships are the connections that are desired. The point here is to disdain superficial similarities that have a type of surface connection; one wants specific interrelationships with similar underlying meaning.

Following this, one would look for 'striking' or qualitative descriptive similarities with specific word and conceptual usage to link the accounts (\#5). This means that the later narrative features would be difficult to account for apart from borrowing because of their uniqueness, apart from the common, expected descriptions. ${ }^{7}$ Detailed similarities with a close proximity in conceptual usage or definition as well as uniqueness were targets of the aim in assessing 'striking' or 'impressive' narrative commonalities.

\footnotetext{
7.Details which are completely unexpected, to the point of being unexplainable apart from borrowing, are strong evidence for borrowing. Details which are almost from borrowing, are strong evidence for borrowing. Details which are almost are considered prima facie evidence for borrowing. An example would be a similar mythic or religious event that had a deep, clear contextual similarity in either what mythic or religious event that had a deep, clear contextual similarity in either what
was attempted or what was accomplished. In this context one finds a word with a was attempted or what was accomplished. In this context one
clear usage in the old context but appended oddly to the new.
}

Then one must endeavour to determine whether the events given in the accounts are central or peripheral features (\#6) in the narrative under analysis. This is the most difficult evaluation criterion of the rubric, and as such should be carefully determined with a tentative conclusion. ${ }^{8}$

If one uses the example of the death and resurrection of Jesus in comparison, one might be able to see the utility of the 'centrality' category. There is no other event more pivotal to Christianity than the resurrection of Jesus of Nazareth. Thus the question for this last step of the rubric is whether the analysed pagan revivications or returns are the hub or the axis of the narrative, tangential or axiomatic in the accounts analysed.

The final control for the rubric was the simple approximation of whether there are multiple disparate pagan parallel accounts in question. This category is one which was discussed earlier entitled 'competition' (\#7). One cannot just pick and choose across a wide spectrum of chronological and narrative divergence and expect a tight genetic relationship to be established.

\section{Qualifications}

Any particular pagan parallel proposed does not need to meet all of these criteria perfectly to be considered a match to the Gospel data. Such a requirement would be, admittedly, too stringent and would be illegitimately stacking the analytical deck in favour of the uniqueness of the Gospels against the strong homogeneity position. But to be responsible in our scholarship, the parallel would need to meet a majority of the alternate criteria if it is judged as a poor fit in one specified category in order to succeed.

I want to offer two possible explanations for why the strong homogeneity thesis, with regard to pagan narratives and the New Testament Gospels, is not strongly represented by the scholarly community (Ehrman 2012:chs. 6, 7; Mettinger 2001:36-37). ${ }^{9}$ Some would argue that this is because the majority of those studying the New Testament are hopelessly biased in its favour, and thus have a tendentious and unfair resistance to giving this idea a fair assessment (Carrier 2005:145-151; Price \& Lowder 2005:11). This argument, however, can cut in both directions, as those with a negative predilection against uniqueness and historic verisimilitude of the New Testament could also give too much credence to the strong homogeneity thesis. Everyone brings personal leanings to their analysis, as Albert Schweitzer both reminded us and proved in his Geschichte der Leben Jesu Forschung ('The quest of the historical Jesus').

8.We are separated from these authors and followers by millennia.

9.In the words of Ehrman (2012):

At a reputable university, of course, professors cannot teach simply anything. They need to be academically responsible and reflect the views of scholarship. That is probably why there are no mythicists - at least to my knowledge - teaching religious studies at accredited universities or colleges in North America or Europe. It is not that mythicists are lacking in hard-fought views and opinions or that they fail to that mythicists are lacking in hard-fought views and opinions or that they fail to mount arguments to back them up. It is that their views are not widely seen as academically respectable by members of the academy. That alone clearly does not And the mythicists wrong. It simply makes them marginal. (ch. 6 )

And, 'Even though most mythicists do not appear to know it, the onetime commonly held view that dying-rising gods were widespread in pagan antiquity has fallen on hard times among scholars' (Ehrman 2012:ch. 7). 
The first reason why the strong homogeneity thesis is not favoured by scholars in the relevant fields, is that when the divergent themes, activities, and details are presented the homogeneity idea is hobbled. The discordant data reveals profound difficulties in maintaining the category match, and the thesis becomes crowded with qualification after qualification offered by proponents. Lord Ockham warns of perspectives of this sort. Consequently, when proponents offer the idea for consideration and reflection they often remain somewhat vague in their description or simply disclose the parallel elements without consideration of context and without identification and presentation of the disparate features where the stories diverge. Placing such an overt priority on similarity with regard to the parallel features inverts a crucial primacy in cognition and evaluation. By way of illustration, the fact that hydrofluoric acid and apple juice 'are both liquids' is hardly the most crucial fact to ascertain concerning these two things. Differences matter, and there are numerous ways in which one can come to erroneous conclusions when divergent details are bypassed or unavailable to the one tasked with coupling concepts or items.

The second reason is that when one begins searching for ideas that match the salient features of the Jesus narratives from before the first century ad, one finds the available data to be sparse. As one moves backward chronologically the data becomes more and more attenuated for the majority of the pagan divinised, miracle-working characters offered to be a possible match for Jesus (Blackburn 1991:24-59; Kahl 1994:236; Mettinger 2001:4, 7, 215; Twelftree 1999:247-248). Conversely, the match number and quality became more conspicuous after the Jesus story has circulated in Palestine and then throughout the Roman Empire, i.e. in the second through fifth centuries ad (Bowersock 1994:22, 103, 119, 139).

This is in part because of the lack of manuscript availability and the fragmentary nature of what has been excavated or culled indirectly from other extant sources (Anderson 1977:22; Barrett 1987:120-134; Metzger 1968:4, 7-8). Yet the fact remains that the majority of pertinent pagan parallel evidence, at least with regard to death and return, is poorly positioned chronologically (Anon. 1993:219; Ehrman 2012: ch. 7; Pannenberg 1968:91-92; Smith 1987:2535-2440). These general facts create an unfavourable climate for scholarly consideration.

That fact that differences between the Gospels and the accounts of pagan deities and heroes are either ignored by those espousing a connection, or never offered to those who are inquiring, is likely the alpha handicap for the strong homogeneity thesis. One can clearly overplay differences, but they must be presented and weighed, or a distorted conclusion becomes much more likely. Perhaps one can never perfectly balance similarities and differences; however, something more than either silence or a mere mention that 'there are discrepancies' should be adduced. Blurring crucial distinctions makes rational deliberation exceedingly difficult, if not impossible.
This combination of proposed controls is not intended to be the only way to assess the validity of the strong homogeneity thesis. Not only are there other ways to evaluate this question, but I concede that some of the alternate investigative steps might yield fruitful results. One could, for example attempt to assess whether the archaeological and textual data reveal a strong social presence of these competing worship traditions in first-century Palestine. Or one could attempt to evaluate the likelihood of first-century Hebrews to have assimilated and mimicked the religious and social mores of their host culture (Boyd \& Eddy 2007; Charlesworth 1988; Dunn 2003; Sanders 1985), or the distinction and overlap between two ancient genres, such as biography (bios), myth (mythos) or novel (Aune 1981; Burridge 1992; Keener 2009; Talbert 1977). One could compare and contrast what kinds of literary forms would be seen as historic and which would be determined to be entertainment or a digression away from historic reporting; or one could attempt to assess what evidential support is offered for the stories given; or to estimate the trustworthiness of the individual from whom the story was disseminated.

One might surmise that this approach, as it applies to the subject matter at hand, may be construed as too formal or as an effort to stack the analytical deck in favour of an inevitable conclusion hostile to the idea of strong pagan homogeneity, at least with respect to the Gospels. One might respond by pointing out that the method conscientiously follows esteemed, seasoned professionals in the field who (to add an additional layer of control) lack my worldview commitment. One can hardly be faulted for standing on the shoulders of others who undertake this comparative enterprise with excellence as a vocation.

Further, if a criterion can be too strict, can it not also be too informal and lenient? At what point does the criterion become overly exacting if these ancient authors indeed drew liberally from one another in matters such as these? It seems clear that the greater evaluative danger lies in deducing parallels from disparate data by offering only vague and casual links and bypassing context. Differences should be presented along with linking data so that one can come to a sufficiently informed decision about any proposed parallel.

The subjective element will never be fully expunged from any analytic or investigative effort, this is clearly the case in this process of assessing the likelihood of literary and conceptual plagiarism. However, vague terminology, disregarding common cultural definitions and opaque event description tends to increase the likelihood of an erroneous connection being bridged. One wants to be responsible, fair and as comprehensive as possible in one's investigation of any subject. Any time a scholar can acquire a consensus in methodological controls, the conclusions wrought are thereby enhanced. To this end, presenter and investigator alike reap the epistemological rewards. 


\section{Acknowledgements Competing interests}

The author declares that he has no financial or personal relationships which may have inappropriately influenced him in writing this article.

\section{References}

Adams, J. \& Barden, M., 1952, 'The ancient world', in P.K. Davis (ed.), Encyclopedia of invasions and conquests, pp. 1-54, Grey House, Millerton.

Africa, T., 1974, The immense majesty, Crowell, New York.

Allegro, J., 1970, The sacred mushroom and the cross, Hodder \& Stoughton, London.

Alsup, J.E., 1975, The post resurrection appearance stories in the Gospel tradition, Wipf \& Stock, Eugene.

Anderson, J.N.D., 1977, Christianity and comparative religion, InterVarsity, Downers Grove.

Anon., 1993, 'Dying and rising with Christ', in G. Hawthorne, R. Martin \& D. Reid (eds.) Dictionary of Paul and his letters, p. 219, InterVarsity, Grand Rapids.

Anon., 2008, 'Prehistoric eras to 600 ce', in M. Ackerman, M. Schroeder, J. Terry, J. Upshur, M. Whitters (eds.), Encyclopedia of World History, vol. 1, p. xxxv, Facts on File, New York.

Aune, D., 1981, 'The problem of the genre of the Gospels', in R.T. France \& D. Wenham (eds.), Gospel perspectives 2, pp. 9-60, JSOT Press, Sheffield.

Barrett, C.K., 1987, 'Mystery religions', in C.K. Barrett (ed.), The New Testament background, pp. 120-134, Harper Collins, New York.

Beard, M., 2012a, 'Rome', in R. Willis, (ed.), World mythology, pp. 166-170, Metro Books, New York.

Beard, M., 2012b, 'Romulus', in R. Willis (ed.), World mythology, pp. 174-175, Metro Books, New York.

Blackburn, B., 1991, Theios Aner and the Markan miracle traditions: A critique of the Theios Aner concept as an interpretive background of the miracle traditions used by Mark, Mohr, Tubingen.

Bousset, W., 1913, Kyrios Christos: A history of the belief in Christ from the beginnings of Christianity to Irenaeus, transl. J.E. Steely, Abington, Nashville.

Bowersock, G., 1994, Fiction and history, University of California Press, Los Angeles.

Boyd, G. \& Eddy, P., 2007, The Jesus legend, Baker Academic, Grand Rapids.

Bruce, F.F., 1976, 'Myth', in C. Brown (ed.), New international dictionary of New Testament theology, pp. 643-647, Zondervan, Grand Rapids.

Bultmann, R., 1953, 'New Testament and mythology', in W. Bartch (ed.), Kerygma and myth, pp. 1-24, Harper Torchbooks, New York.

Bultmann, R., 1962, 'The study of the synoptic Gospels', in F.C. Grant (ed.), Form criticism: Two essays on New Testament research, pp. 7-75, Harper, New York.

Burkert, W., 1992, The orientalizing revolution: Near eastern influence on Greek culture in the Early Archaic Age, Harvard University Press, Cambridge.

Burridge, R.A., 1992, What are the Gospels? Cambridge University Press, Cambridge.

Cameron, A. \& Anthon, C., 2004, Greek mythography in the Roman world, Oxford University Press, Oxford.

Campbell, J., 1972, The hero with a thousand faces, Princeton University Press, Princeton.

Carrier, R., 2002, Osiris and pagan resurrection myths: Assessing the Till-McFall exchange, viewed 17 August 2015, from http://www.richardcarrier.info/Carrier on_Osiris_.html

Carrier, R., 2005, 'The spiritual body of Christ and the empty tomb', in R. Price \& J.J. Lowder (eds.), The empty tomb: Jesus beyond the grave, pp. 105-230, Prometheus, New York.

Carrier, R., 2009, Not the impossible faith: Why Christianity did not need a miracle to succeed, Lulu, New York, viewed 6 August 2012, from http://www.infidels.org/ library/modern/richard_carrier/improbable/crucified.html\#1.2

Carrier, R., 2014, On the historicity of Jesus: Why we might have reason for doubt, Sheffield Phoenix, Phoenix.

Carus, P., 1902, 'Pagan elements of Christianity: The significance of Jesus', The Monist 12(2), 415-425. https://doi.org/10.5840/monist190212312

Casadio, G., 2003, 'The failing male God: Emasculation, death and other accidents in the ancient Mediterranean world', Numen, 50(3), 231-268. https://doi.org/ $10.1163 / 156852703322192400$

Charlesworth, J.H., 1988, Jesus within Judaism, Doubleday, New York.

Dinckler, E., 1962, 'Myth in the New Testament', in G. Butterick (ed.), Interpreter's dictionary of the Bible, p. 487, Abington, New York.

D'Souza, D., 1995, The end of racism, Simon \& Schuster, New York.

D'Souza, D., 2002, What's so great about America?, Regnery, Washington.

Dunn, J.G.D., 2003, Jesus remembered, Eerdmans, Grand Rapids.

Dupuis, C.F., 1795, The origin of all religious worship, University of Michigan Library, Ann Arbor.
Ehrman, B.D., 2012, Did Jesus exist? The historical argument for Jesus of Nazareth Kindle ed., Harper Collins, New York.

Evans, C., 2006, Fabricating Jesus, InterVarsity, Downers Grove.

Fogelin, R., 2003, A defense of Hume on miracles, Princeton University Press, Princeton.

Frazer, J. \& Fraser, R., 1998, The golden bough, Oxford University Press, Oxford.

Freke, T. \& Gandy, P., 1999, The Jesus mysteries. [self-published]

Gasque, W., 2004, The leading religion writer in Canada, does he know what he is talking about?, viewed 21 February 2015, from http://historynewsnetwork.org/ article/6641

Grant, R.M., 1986, The gods and the one God, Westminster, Philadelphia.

Griffith, J.G., 1961, The conflict of Horus and Seth, Liverpool University Press, Liverpool.

Griffith, J.G., 1996, The origins of Osiris and his cult, Brill, Boston.

Habermas, G.R., 1996, The historical Jesus: Ancient evidence for the life of Christ, College Press, Joplin.

Harpur, T., 2004, The pagan Christ: Recovering the lost light, Thomas Allen, Toronto.

Harris, S. \& Platzner, G., 1995, Classical mythology, Mayfield, Mountain View.

Hughes, P.E., 1984, 'Myth', in W. Elwell (ed.), Evangelical dictionary of theology, pp. 747-749, Baker, Grand Rapids.

Hurtado, L., 1988, One God, one lord: Early Christian devotion and ancient Jewish monotheism, Fortress, Minneapolis.

Hurtado, L., 2005, How on earth did Jesus become a god? Historical questions about earliest devotion to Jesus, Eerdmans, Grand Rapids.

Hurtado, L., 2016, Destroyer of the gods: Early Christian distinctiveness in the Roman world, Kindle ed., Baylor University Press, Waco.

Jackson, J.G., 1985, Christianity before Christ, American Atheist Press, Austin.

Johnson, L.T., 1996, The real Jesus, Harper Collins, San Francisco.

Johnson, L.T., 2009, Among the Gentiles, Yale University Press, New Haven.

Jones, W.T., 1969, The medieval mind, Harcourt, Brace \& World, New York.

Kahl, W., 1994, New Testament miracle stories in the religious-historical setting: A Religionsgeschichliche comparison from a structural perspective, Vandenhoeck \& Religionsgeschichliche
Ruprecht, Gottingen.

Keener, C.S., 1993, The IVP Bible background commentary - NT, InterVarsity, Downers Grove.

Keener, C.S., 2009, The historical Jesus of the Gospels, Eerdmans, Grand Rapids.

Krauss, L., 2011, Pharyngula, viewed 13 June 2012, http://scienceblogs.com/ pharyngula/2011/04/lawrence_krauss_vs_william_lan.php

MacDonald, D.R., 2000, The Homeric epics and the Gospel of Mark, Yale University Press, New Haven.

MacDonald, D.R., 2015, Mythologizing Jesus: From Jewish teacher to epic hero, Kindle ed., Rowman \& Littlefield, Lanham.

Mack, B., 1988, A myth of innocence, Fortress, Philadelphia.

Mack, B., 1995, Who wrote the New Testament? The making of the Christian myth, Harper Collins, San Francisco.

Mack, B., 2001, The Christian myth, Continuum, New York.

Meier, J.P., 1991, A marginal Jew: Rethinking the historical Jesus, Doubleday, New York.

Mellor, R., 1999, The Roman historians, Routledge, New York.

Meltzer, E.S., 2003, 'Horus', in D. Bedford (ed.), The Oxford guide: Essential guide to Egyptian mythology, pp. 164-168, Berkeley University Press, Berkeley.

Mettinger, T.N.D., 2001, The riddle of the resurrection, Wallin \& Dalholm, Lund.

Metzger, B., 1968, Historical and literary studies: Pagan, Jewish, and Christian, Eerdmans, Grand Rapids.

Miller, R.C., 2010, 'Mark's empty tomb and other translation fables in classical antiquity', Journal of biblical literature 129(4), 756-776. https://doi.org/10.2307/ 25765965

Miller, R.C., 2015, Resurrection and reception in early Christianity, Routledge, London. Murdock, D., 1999, The Christ conspiracy, Adventures Unlimited, Kempton.

Nabarz, P. \& MatthewsC., 2005, The mysteries of Mithras: The pagan belief that shaped the Christian world, Inner Traditions, Rochester.

Nash, R., 2003, The Gospel and the Greeks: Did the New Testament borrow from pagan thought? P\&R Publishing, Phillipsburg.

Oswalt, J., 2009, The Bible among myths, Kindle ed., Zondervan, Grand Rapids.

Pannenberg, W., 1968, Jesus, God and man, Westminster, Philadelphia.

Penglase, C., 1994, Greek myths and Mesopotamia: Parallels and influence in the Homeric hymns and Hesiod, Routledge, New York.

Pfleiderer, O., 1910, Primitive Christianity, 4 vols., Reference Book Publisher, Clifton. Porter, S. \& Bedard, S., 2006, Unmasking the pagan Christ, Clements, Toronto.

Price, R., 2000, Deconstructing Jesus, Prometheus, New York.

Price, R., 2009, 'Jesus at the vanishing point', in J.K. Beilby \& P.R. Eddy (eds.), The historical Jesus: Five views, pp. 55-83, InterVarsity, Downers Grove.

Price, R. \& Lowder, J.J., 2005, The empty tomb: Jesus beyond the grave, Prometheus, New York. 
Priestly, J., 1804, The doctrines of heathen philosophy compared with those of Christianity, John Binns, Northumberton.

Puhvel, J., 1987, Comparative mythology, Johns Hopkins, Baltimore.

Rahner, H., 1955, 'The Christian mystery and the pagan mysteries', in J. Campbell (ed.) Pagan and Christian mysteries: Papers from the Eranos yearbooks, pp. 337-404, Harper Torchbooks, New York.

Rajak, T., 2008, 'The Jewish Diaspora', in M. Mitchell \& F. Young (eds.), Cambridge history of Christianity: Origins to Constantine, vol. 1, pp. 61-62, Cambridge University Press, Cambridge.

Rank, O., Raglan, L. \& Dundes, A., 1990, In quest of the hero, Princeton University Press, Princeton

Riches, J. \& Millar, A., 1985, 'Conceptual changes in the synoptic tradition', in A.E. Harvey (ed.), Alternative approaches to New Testament study, pp. 37-60, SPCK, London.

Robertson, J., 1985, The origins of Christianity: A critical introduction, Prometheus, New York.

Ruttimann, R.J, 1986, 'Asclepius and Jesus: The form, character and status of the Asclepius cult in the second century ce and its influence on Christianity', Ph.D. thesis, U.M.I. Dissertation Information Service, Ann Arbor.

Sanders, E.P., 1985, Jesus and Judaism, Fortress, Philadelphia.

Sanders, E.P., 1992, Judaism: Practice and belief, SCM, London.

Sandmel, S., 1962, 'Parallelomania', Journal of Biblical Literature 81(1), 1-13. https:// doi.org/10.2307/3264821

Short, A., 1985, The Egyptian gods: A handbook, Borgo, San Bernandino.

Smith, J.Z., 1987, 'Dying and rising gods', in E. Mircea (ed.), Encyclopedia of religion, pp. 2535-2440, Macmillan, New York.
Stark, R., 2016, Cities of God, Harper Collins, New York.

Strauss, D., 1860, Das Leben Jesu: Kritisch bearbeitet, ('The life of Jesus critically examined'), Calvin Blanchard, New York.

Talbert, C.H., 1977, What is a gospel? The genre of the canonical Gospels, Fortress, Philadelphia.

Twelftree, G., 1999, Jesus: The miracle worker, InterVarsity, Downers Grove.

Vermes, G., 1973, Jesus the Jew, Collins, London.

Vermes, G., 1983, Jesus and the world of Judaism, SCM, London.

Waters, M., 2014, Ancient Persia, Cambridge University Press, Cambridge.

Watterson, B., 1985, The gods of ancient Egypt, Facts on File, New York.

West, M.L., 1997, The east face of Helicon: West Asiatic elements in Greek poetry and myth, Oxford University Press, Clarendon.

Wilkinson, R.H., 2003, The complete gods and goddesses of ancient Egypt, Thames \& Hudson, New York.

Williams, M., 1998, Jew among Greeks and Romans, Duckworth, London.

Wright, N.T., 1992, The New Testament and the people of God: Christian origins and the question of God, vol. 1, Fortress, Minneapolis.

Wright, N.T., 1996, Jesus and the victory of God: Christian origins and the question of God, vol. 2, Fortress, Minneapolis.

Wright, N.T., 2003, The resurrection of the son of God: Christian origins and the question of God, vol. 3, Fortress, Minneapolis.

Wolmarans, H., 2008, Resurrection in Greco-Roman mystery religions, University of Pretoria, Pretoria, (Unpublished), [PowerPoint presentation]

Yahaya, N., 2008, 'Alexander', in M.E. Ackerman, M. Schroeder, J. Terry, J. Upshur \& M. Whitter (eds.), Encyclopedia of world history, pp. 1:9-12, Facts on File, New York. 